\title{
Jornaleros bolivianos en el Cantón Central (1879-1946). El caso de la Oficina salitrera María
}

\section{Day laborers bolivian in the Canton Central (1879-1946). The case of nitrate office Maria}

\author{
Damir Galaz-Mandakovic ${ }^{1}$ (D) https://orcid.org/0000-0003-0312-6672 \\ Alejandro Garcés (D) https://orcid.org/0000-0002-4792-6623 \\ ${ }^{1}$ Universidad de Tarapacá, Arica, CHILE. Email: damirgalaz@gmail.com \\ ${ }^{2}$ Instituto de Investigaciones Arqueológicas y Museo, Universidad Católica del Norte, San Pedro de Atacama, CHILE. \\ Email: agarces@ucn.cl
}

\section{Resumen}

Caracterizamos la presencia boliviana durante el declive del ciclo de expansión del salitre en el Cantón Central, analizando los prontuarios bolivianos del Archivo Histórico de la Universidad Católica del Norte. A partir de datos relativos a los lugares de origen, inserción laboral y sociabilidad en destino, principalmente, el artículo da cuenta de la magnitud del fenómeno y de la centralidad que ocupó esta mano de obra jornalera en el despliegue de las faenas mineras. De este modo, podrá observarse cómo el capitalismo minero produce una mano de obra subalterna en un territorio que, no obstante, se resiste a perder su bolivianidad.

Palabras clave: migración boliviana, minería del salitre, Cantón Central, Antofagasta, jornaleros.

\begin{abstract}
From the analysis of the Bolivian records of the Historical Archive of the Catholic University of the North, we characterize the Bolivian presence during the decline of the nitrate expansion cycle in the Central Canton. Based on data related to the places of origin, labor insertion and sociability at the destination, the article gives an account of the magnitude of the phenomenon and the centrality that this day laborer occupied in the deployment of mining operations. In this way, it can be observed how mining capitalism produces a subaltern workforce in a territory where it resists losing its bolivianity.
\end{abstract}

Keywords: bolivian migration, saltpeter mining, Central Canton, Antofagasta, day laborers.

Recibido: 3 septiembre 2019. Aceptado: 28 octubre 2019 


\section{Introducción}

El desarrollo del extractivismo salitrero en un territorio disputado en una guerra acusó, desde finales del siglo XIX, serios problemas con el reclutamiento de trabajadores: la necesidad de esta mano de obra se vio acrecentada ante el aumento de las minas no metálicas y también por el aumento de las escalas de producción. En ese escenario, las empresas salitreras vieron en Bolivia un territorio para reclutar trabajadores a través de una modalidad de persuasión llamada "enganche", acciones ejecutadas en las comunidades de origen de estos migrantes.

Estos procesos transcurrieron en una escena de posguerra que significó la expansión del ciclo del salitre del sistema Shanks ${ }^{1}$, hasta finales de la década de 1920, ciclo que demostró que las nuevas fronteras entre Chile y Bolivia estaban, en los hechos, diluidas, evidenciándose flujos de personas y de diversas economías.

En este artículo se describe la migración boliviana hacia Chile, particularmente hacia la zona de Atacama, caracterización sustentada en el levantamiento de una base de datos que contiene el registro de 3794 casos de migrantes. Dicha información fue levantada en el Archivo Histórico de la Universidad Católica del Norte (AHUCN), correspondiente a los prontuarios del Archivo de Extranjería del Registro Civil e Identificación de Antofagasta. ${ }^{2}$ Así, podremos dar a conocer los datos sobre quiénes, cuándo y cuántos atravesaron la frontera ingresando mayoritariamente por el paso de Ollagüe en un rango temporal que va desde 1879 hasta 1946, centrando nuestro foco en los jornaleros que se distribuyeron en el desierto minero, analizando la particularidad de una oficina salitrera ubicada en el Cantón Central, también conocido como el Cantón Bolivia.

Como hipótesis central, queremos demostrar que la migración boliviana atestiguada en el período de la posguerra, además de articular dos territorios internacionales discontinuos, fue un importante colectivo que participó en la sociedad minera que se construía en el nuevo norte de Chile, especialmente en el desarrollo del extractivismo salitrero. Dicha participación es más significativa una vez que se inicia el declive de las salitreras del sistema Shanks en la década de 1920. Fue así que en el caso del Cantón Central, la producción de salitre se apoyó en la subalternización de la migración boliviana, constituyéndose esta migración de baja cualificación en una complementariedad y también una subsidiariedad internacional mientras transcurría, supuestamente, un proceso de desbolivianización o chilenización en el desierto de la posguerra.

\section{Bolivianos en la escena del salitre}

El primer censo chileno realizado en el desierto en 1885, "antiguo departamento boliviano llamada Atacama, El Litoral o La Mar, que pasó a la sujeción de la soberanía de Chile por el pacto de tregua..." (Oficina Central de Estadística en Santiago, 1889, p. 786), consignó una población para el departamento de Antofagasta de 16549 habitantes y de 4664 en el departamento de Tocopilla, indicando que en Antofagasta había 5291 extranjeros $(31,9 \%)$ y 1228 en

1 Antiguo método de elaboración de sales introducido en la producción del salitre por Santiago Humberstone en el año 1876. Se caracterizó por la lixiviación de los caliches a alta temperatura.

2 El archivo contiene 36 cajas con 150 prontuarios aproximadamente cada una. Lo que da un total por sobre los 5.300 prontuarios que indican una diversidad de datos sobre los bolivianos que ingresaron a Chile. 
Tocopilla (26,3\%). Lamentablemente, el Censo de 1885 no entrega los detalles del origen de aquellos extranjeros. No obstante, según los prontuarios del Archivo Histórico de la Universidad Católica del Norte, en la zona agregada forzosamente a Chile se registran, entre los años 1879 y 1885, 144 bolivianos (AHUCN), distribuidos en diversos poblados de la costa, algunas oficinas salitreras y pueblos precordilleranos.

Según los datos proporcionados por el Censo de 1907, la zona de la actual región de Antofagasta estuvo fuertemente marcada por grupos europeos, bolivianos y peruanos. El censo citado nos indica una cifra del 4,2\% de la población nacional. Cifras porcentuales que al ser traducidas en términos absolutos nos arrojan 134524 habitantes. De ellos, 21968 eran bolivianos, lo que equivalía al 16,3\% de la población nacional.

El Censo de 1907 señala para la provincia de Antofagasta la presencia de 5296 bolivianos, tanto en el área rural como en el espacio urbano, significativa cifra en una ciudad que tenía una población de 31466 habitantes, es decir, los bolivianos representaban el 16,8\%. Por su parte, en la segunda urbe más poblada en la actual región de Antofagasta, la ciudad de Tocopilla, se contabilizan 511 bolivianos, en un departamento de 15861 habitantes, por lo cual los bolivianos representaban el 3,2\%. No obstante, la población boliviana era el grupo más numeroso, superando a los ingleses (284 personas) y a los peruanos (266 personas).

En la contabilización demográfica realizada en el año 1920, el departamento de Antofagasta contiene una población de 101604 habitantes, mientras la ciudad homónima contiene 51 531. De ese modo, se contabilizan 6177 bolivianos (3559 hombres; 2618 mujeres). Es decir, los bolivianos representaban el 11,9\% de la población residente en Antofagasta. De ese modo, nuevamente, eran la población de extranjeros más significativa.

Hacia el año 1930 la población boliviana se redujo en comparación a los censos de 1907 y 1920: en 1930 se contabilizan 4715 bolivianos en la provincia de Antofagasta (2718 hombres; 1997 mujeres). ${ }^{3}$ Es decir, 1462 bolivianos menos que para el Censo de 1920 (en Chile se contabilizaba un total de 10366 bolivianos). Entonces, podemos decir que en la Antofagasta de 1930 residía el 45,4\% de la población total de bolivianos residentes en Chile, en una ciudad que albergaba un total de 53591 habitantes.

Todos estos guarismos nos reportan la existencia de una densidad boliviana que participaba en la sociedad del nuevo norte de Chile, migraciones que constituyeron al territorio como un espacio transfronterizo que, por efecto de redes sociales, articularon trasiegos en un contexto de minería metálica y no metálica. En aquellos contextos, la exigencia de mano de obra fue elemental, principalmente en oficios no calificados (González, 2008). No obstante, esa mano de obra fue crucial para el desarrollo del extractivismo, que constituyó una subalternidad laboral sustentada en una nacionalidad complementaria, en gran parte invisibilizada en los procesos de desbolivianización o de chilenización. Este proceso fue impulsado por el Estado de Chile en las provincias de Tarapacá y Antofagasta, "el que tenía por propósito borrar las diferencias culturales y establecer una homogeneidad identitaria nacional que asegurara la soberanía chilena en la zona" (Mercado, 2007, p. 3).

La presencia boliviana que describimos presenta, a su vez, un correlato en la producción de imaginarios acerca de su incorporación a las faenas mineras. La mano de obra boliviana era

3 El X Censo (1930) detallaba sobre los bolivianos: 4467 eran solteros; 4783 eran casados; y 1616, viudos. 
importante para esta economía, y en una producción de subalternidad, lo que no impidió que se realizaran una serie de comentarios por parte de exploradores e ingenieros, quienes desdeńosamente la retratan:

La casi totalidad de los trabajadores chilenos son de las provincias del sur. Por su físico robusto i bien musculado, su habilidad, su intelijencia i resistencia para soportar el sol ardiente i polvo de la pampa, son mui superiores a los peruanos, por lo jeneral de constitución débil, i también a los bolivianos, que, a pesar de ser resistentes, son ménos intelijentes (Semper y Michels, 1908, p. 100).

Las imágenes y semánticas despectivas reproducen el nacionalismo chileno sustentado en el racismo de los estudios técnicos de la minería de los nitratos. Fue así que, los mismos autores alemanes que hemos citado emiten comentarios negativos centrándose en la salubridad del habitar: "los trabajadores bolivianos se encuentran en su grado de cultura sumamente bajo: sus habitaciones están atestadas de inmundicias i bichos" (Semper y Michels, 1908, p. 103). Sin embargo, reconocen que la presencia de bolivianos es relevante en el contexto de, "por ser mui escaso el aumento natural de trabajadores en la pampa, hubo de incrementársele llevando inmigración del sur de Chile i de Bolivia" (Semper y Michels, 1908, p. 104). Del mismo modo, la presencia de los denominados "cuicos" (Echeverría y Reyes, 1929, p. 24) es comentada por Torrealba en 1926, centrándose en particulares detalles, al menos cuando arriba a la Estación Baquedano, "punto en que cruza el Longitudinal y lugar de algún movimiento" (1926, p. 13). El investigador señala:

El viajero [se] sorprende aquí [con] algunos tipos curiosos de obreros bolivianos con sus mujeres, que visten a la usanza indígena, amplios vestidos de colores vivos, generalmente rojos, amarillos o verdes y sombrero de pita. Una especie de blusa de un género blanco y delgado completan su indumentaria, por cuya pechera mal cerrada percibimos descuidadas desnudeces que no tratan tampoco de ocultar (Torreblanca, 1926, p. 13).

Pamela Fernández cita una serie de casos referidos a las condiciones de vida y de trato que recibió la migración boliviana en la zona de Tarapacá en la primera década del siglo XX, la que fue retratada despectivamente como la "bolivianada" o indios "semi-salvajes". Los bolivianos fueron acusados de ser "portadores de gérmenes", "acarreadores de bubónica" e inculpados por el "desaseo personal". En la revisión de algunos periódicos obreros, la investigadora indica que los bolivianos eran "forzados" a vivir como "gente civilizada" y no como "perros o chanchos", en el marco de ser concebidos como un grupo migrante que, supuestamente, estaba en los "pañales de la civilización", y que además no "manejaba idioma". De ese modo, el colectivo migrante tuvo que soportar una gran cantidad de epítetos ofensivos y violentos reproducidos en diversos diarios, conjugando condiciones de vida precaria (Fernández, 2015).

El período de la posguerra atestiguó de igual modo una serie de conflictos entre bolivianos y chilenos. En diversos periódicos chilenos circulaban fuertes acusaciones hacia los bolivianos, tratándolos como "turbas ebrias de cuicos semi-salvajes" que "asesinaban" a chilenos en Bolivia. Los violentos comentarios eran, por ejemplo: "estoi por creer que la coca i el maiz tostado boliviano les hubieran adormecido la indomable enerjía”. Al menos así lo informa el periódico santiaguino Poncio Pilatos el jueves 26 de abril de 1894, y agrega que "aqui en Chile, i, sobre todo, en Antofagasta i Tarapacá, a los bolivianos se les mima, se les trata como niñas bonitas i se les 
anda trayendo en palmas de manos", trato que según el periódico citado era "injusto" ante la supuesta "bestialidad" y "mal vivir" de estos migrantes.

\section{Migración boliviana en el desierto de Atacama}

En la revisión de los 3794 casos de migrantes bolivianos en Chile, podemos ver que estos se distribuyeron en 87 poblados del desierto antofagastino, los que pueden ser caracterizados en siete áreas temáticas en cuanto a las actividades que desarrollaban, y abarcan desde la costa hasta la precordillera, evidenciándose centros microurbanos que vehiculizaron redes sociales, materialidades e insumos. Estos son: 1) ciudades, 2) oficinas salitreras, 3) minas de plata, 4) minas de cobre, 5) pueblos precordilleranos, 6) azufreras y borateras y 7) estaciones ferroviarias.

Las salitreras son el área que mayor cantidad de poblados conglomera como lugares de destino en Chile, con 52 poblados. Por su parte, el conjunto vinculado con ciudades, minas de plata, borateras y azufreras, son los poblados que menos migrantes atraen. De este modo, es posible cuantificar y jerarquizar los lugares mencionados como destinos que más bolivianos aglutinaron (Tabla 1).

Tabla 1. Cuantificación por las 30 primeras ciudades y poblados indicados como "destino en Chile".

\begin{tabular}{|c|c|c|c|}
\hline Destino en Chile & Tipo de poblado & Total de migrantes & $\%$ \\
\hline 1. Antofagasta & Ciudad puerto & 1.233 & $32,4 \%$ \\
\hline 2. Chuquicamata & Mina de cobre & 353 & $9.3 \%$ \\
\hline 3. Calama & Ciudad & 278 & $7,3 \%$ \\
\hline 4. Of. María & Salitrera & 204 & $5,3 \%$ \\
\hline 5. Collahuasi & Mina de cobre & 193 & $5,0 \%$ \\
\hline 6. Cebollar & Boratera & 166 & $4,3 \%$ \\
\hline 7. Of. Cecilia & Salitrera & 114 & $3,0 \%$ \\
\hline 8. Ollagüe & Estación ferroviaria, azufrera y frontera & 110 & $2,8 \%$ \\
\hline 9. Of. Aconcagua & Salitrera & 99 & $2,6 \%$ \\
\hline 10. Of. Luisa & Salitrera & 95 & $2,5 \%$ \\
\hline 11. Of. Araucana & Salitrera & 80 & $2,1 \%$ \\
\hline 12. Of. Lina & Salitrera & 73 & $1,9 \%$ \\
\hline 13. Of. Anita & Salitrera & 57 & $1,5 \%$ \\
\hline 14. Of. Filomena & Salitrera & 55 & $1,4 \%$ \\
\hline 15. San Pedro de Atacama & Pueblo precordillerano & 50 & $1,3 \%$ \\
\hline 16. Of. Candelaria & Salitrera & 48 & $1,2 \%$ \\
\hline 17. Of. Edwards & Salitrera & 48 & $1,2 \%$ \\
\hline 18. Of. José Santos Ossa & Salitrera & 48 & $1,2 \%$ \\
\hline
\end{tabular}




\begin{tabular}{|l|c|c|c|}
\hline 19. Of. Pinto & Salitrera & 37 & $0,9 \%$ \\
\hline 20. Of. Pedro de Valdivia & Salitrera sistema Guggenheim & 36 & $0,9 \%$ \\
\hline 21. Pampa Unión & Salitrera & 36 & $0,9 \%$ \\
\hline 22. Of. Chacabuco & Salitrera & 35 & $0,9 \%$ \\
\hline 23. Of. Puelma & Salitrera & 25 & $0,6 \%$ \\
\hline 24. Yuma & Estación ferroviaria & 25 & $0,6 \%$ \\
\hline 25. Of. Prat & Salitrera & 23 & $0,6 \%$ \\
\hline 26. Toconao & Pueblo precordillerano & 22 & $0,6 \%$ \\
\hline 27. Of. María Elena & Salitrera sistema Guggenheim & 16 & $0,5 \%$ \\
\hline 28. Of. Leonor & Salitrera & 15 & $0,1 \%$ \\
\hline 29. Ujina & Estación ferroviaria & 12 & $0,1 \%$ \\
\hline 30. Puquios & Estación ferroviaria & 184 & $0,1 \%$ \\
\hline Otros & & $\mathbf{3 . 7 9 4}$ & $\mathbf{1 0 0} \%$ \\
\hline Total & & $4,8 \%$ \\
\hline
\end{tabular}

Esquema: Elaboración propia. Fuente: Archivo Histórico Universidad Católica del Norte, Fondo Archivo de Extranjería del Registro Civil e Identificación de Antofagasta.

Si analizamos el ingreso de los 3794 bolivianos, ordenado en rangos de 10 años, podemos ver que en el período que va desde 1920 a 1929, se presenta un significativo aumento de la inmigración, considerando 1541 casos, lo que equivale a la duplicación del rango anterior (1910-1919). Es decir, en el citado período, del total de 3794 ingresos, un 40,6\% se concentró en aquel lapso. Del mismo modo, podemos ver que durante el proceso de desmantelamiento de las salitreras con tecnología Shanks después de la gran crisis de 1930, queda evidentemente reflejado el descenso de bolivianos en Atacama. Es decir, en el rango 1930 y 1939, solo se testificó el ingreso de 416 bolivianos, lo que significa una disminución de 26,9\% respecto al rango cronológico 1920 y 1929.

El 95,2\% de los casos informó que ingresó por el paso fronterizo de Ollagüe, primera estación chilena del Ferrocarril de Antofagasta a Bolivia (FCAB), operativo desde 1889 gracias a las inversiones de la Compañía Huanchaca de Bolivia en conjunto con The Antofagasta and Bolivian Railway Company. Fue entonces que ese "hecho técnico" (Schumpeter, 1978) ejerció un impacto decisivo porque dinamizó una migración (Figura 1).

En lo concerniente a los oficios con los cuales se identificaron dichos migrantes, podemos ver que en su mayoría corresponde a jornaleros (Tabla 2).

Según la tabla anterior, los jornaleros representaron significativamente el oficio que caracterizó a este tipo de migración, superando sustancialmente al oficio de sastres, quienes se dirigieron mayoritariamente a Antofagasta (González, Lufín y Galeno, 2015). Dichos jornaleros, como veremos, iban con rumbo a la minería del salitre, tanto hacia el desierto como a los puertos de embarque. 


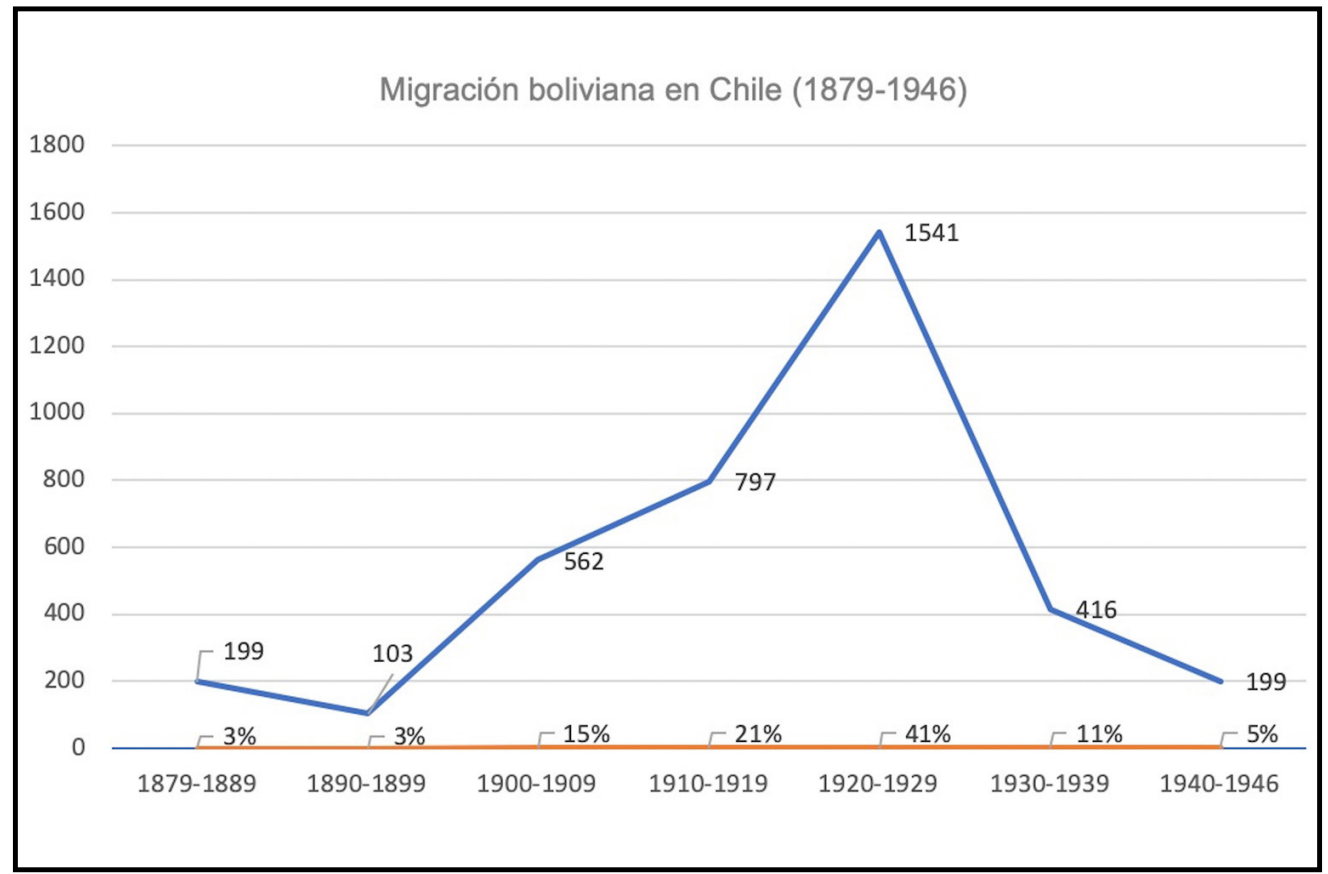

Figura 1. Análisis de la migración boliviana en Chile en rangos de 10 años. Esquema: Elaboración propia. Fuente: Archivo Histórico Universidad Católica del Norte, Fondo Archivo de Extranjería del Registro Civil e Identificación de Antofagasta.

Tabla 2. Identificación y cuantificación de los 10 principales oficios declarados por los migrantes bolivianos entre 1879-1946.

\begin{tabular}{|l|c|c|}
\hline Oficio & Total & $\%$ \\
\hline Jornaleros & 1.146 & $30,2 \%$ \\
\hline Sastres & 253 & $6,6 \%$ \\
\hline Agricultores & 232 & $6,1 \%$ \\
\hline Mecánicos & 207 & $5,4 \%$ \\
\hline Empleados & 196 & $5,1 \%$ \\
\hline Comerciantes & 162 & $4,2 \%$ \\
\hline Labores del sexo & 155 & $4.0 \%$ \\
\hline Estudiantes & 141 & $3,7 \%$ \\
\hline Carpinteros & 115 & $3.0 \%$ \\
\hline Mineros & 101 & $2,6 \%$ \\
\hline Otros & 1.126 & $29,7 \%$ \\
\hline Total & $\mathbf{3 . 7 9 4}$ & $\mathbf{1 0 0} \%$ \\
\hline
\end{tabular}

Esquema: Elaboración propia. Fuente: Archivo Histórico Universidad Católica del Norte, Fondo Archivo de Extranjería del Registro Civil e Identificación de Antofagasta. 


\section{Los jornaleros bolivianos}

Los jornaleros fueron asimilados a una suerte de "peón asalariado cuyo salario puede ser efectivo en moneda y donde el elemento deuda está casi siempre presente" (Pacheco, 1992, p. 88). Es decir, quien trabajó a cambio de un jornal o un pago al final del día de trabajo. Si bien el pago diario era lo predominante, esto no excluía la práctica de los pagos mensuales, cuya "unidad básica de cálculo era una jornada de trabajo" (Matus, 2013, p. 522).

El jornalero en la minería no metálica "era el encargado de limpiar la máquina o retirar el salitre" (S/N, 1988, p. 60). En los hechos, eran aquellos que trabajaban con pala en mano y que en cuadrillas de trabajadores poco cualificados, dirigidos por algún capataz, desplegaban sus trabajos en las chancadoras, cachuchos, chulladoras, calderas, bateas de lixiviación y ensacados. Estas jornadas laborales bordeaban las 12 horas diarias (Matus, 2013).

En el contexto agrario de Bolivia, el considerado jornalero constituía un "semiproletariado", que conseguía ingresos "vendiendo la fuerza de trabajo con el fin de complementar sus necesidades de subsistencia” (Paz, 2009, p. 68). Ser jornalero era prácticamente sinónimo de mozo, siringuero, ${ }^{4}$ fregueses; ${ }^{5}$ eran los considerados como trabajadores empatronados (Pacheco, 1992).

En esa trama, la migración de los jornaleros bolivianos hacia Chile estuvo marcada por la reproducción kinésica de una labor agrícola, desde un valle (principalmente Cochabamba) hacia las labores del salitre en pleno desierto. En sus contextos de origen, normalmente los jornaleros combinaban una precaria y estacional permanencia en las minas, "como trasiego de su actividad central en la agricultura comunitaria indígena” (Rodríguez, 2001, p. 272). En el caso de Tarapacá, los cochabambinos "eran en su mayoría mestizos que hablaban quechua" (González, 2002, p. 47). En ese mismo territorio, los enganches bolivianos fueron resistidos en ciertos momentos por los obreros chilenos "debido a que hacían bajar el salario y por la actitud menos emancipadora de ellos frente a los patrones" (González, 2002, p. 41). O como anota Floreal Recabarren, los empresarios salitreros estimularon esta inmigración, "porque los bolivianos se conformaban con un salario modesto y casi nunca reclamaban” (2002, p. 83).

Cabe indicar que en el año 1906, en el Senado de Chile se discutía sobre la ausencia de mano de obra en el sur del país. El senador Fernando Lazcano criticó al gobierno del presidente Pedro Montt por centrar el foco solo en la inmigración de colonos, usualmente alemanes, para el sur de Chile, e indicó sobre "la urjente necesidad que se hace notar no es de inmigrantes, de colonos, sino de jente trabajadora, de jornaleros...” (ACBN, Cámara de Senadores, Sesión del 15 de noviembre de 1906, p. 347). Dicha mención remitía a la gravitación migrante que acontecía en las salitreras. "[L]a habilitación de tantas Oficinas salitreras nuevas en la provincia de Antofagasta, i el ensanche de las ya establecidas en toda la región del norte, con los jornales subidos que pagan, se han llevado casi todos los trabajadores más útiles del centro i sur del de la República” (ACBN, Cámara de Senadores, Sesión del 15 de noviembre de 1906, p. 347).

En ese escenario, 1146 jornaleros bolivianos acudieron al desierto de Atacama después de la Guerra del Pacífico y participaron como masa laboral y fueron inscritos en las categorías sociales usadas en las salitreras. Luis Emilio Recabarren indicó en 1910: "La última clase, como puede

4 Siringuero es aquel trabajador conocido en la recolección de siringa en los árboles gomeros de Bolivia.

5 Los fregueses, también conocidos en la gomería boliviana, se caracterizaban por trabajar a cambio de mercancías. 
considerarse en la escala social, a los gañanes, jornaleros [...] vive hoy como vivió en 1810 " (1910, p. 168). El mismo dirigente señaló que no existió ningún progreso social y que sus pobrezas se expresaban no solo en lo material, sino que también en lo "moral". Evidentemente, los trabajadores de la pampa salitrera estaban fuertemente estratificados y densamente diferenciados. En primer lugar estaban los ingenieros, los mecánicos y los encargados de manejar las máquinas. Luego, los que trituraban el caliche y los carreteros, que eran los encargados de transportar el caliche hasta las Plantas de elaboración. "El último estrato estaba compuesto por los peones propiamente tales, o jornaleros, que recibían el salario más bajo de todos" (Salazar, 1989, p. 226). Para el caso de las salitreras, en la descripción de las diferentes labores, Torreblanca (1926) señala que la extracción comprendía varios grupos de obreros, entre ellos, los barreteros, carreteros, llenadores de carros, carrilanos y jornaleros; estos últimos, "necesarios para hacer trabajos complementarios, como es el arreglo y regado de huellas" (Torreblanca, 1926, p. 23). Pero no solo en el área de la minería existían esas estratificaciones, sino que también hacia el área agrícola de Atacama, en donde los jornaleros y labriegos eran considerados como del nivel más bajo de la estratificación social y productiva del poblado de San Pedro de Atacama: "no poseían tierras ni animales y que se ocupaban en el rubro agrícola como segadores y jornaleros" (Morales, 2013, p. 160).

En ese escenario y semántica se inscribió la migración de jornaleros desde Bolivia entre los años 1879 y 1946, pudiéndose visualizar los siguientes datos respecto al origen (Tabla 3).

Tabla 3. Identificación de los poblados de origen de los jornaleros bolivianos entre 1879 y 1946.

\begin{tabular}{|c|c|c|c|c|}
\hline $\begin{array}{l}\text { Localidad } \\
\text { de origen }\end{array}$ & $\begin{array}{l}\text { Departamento } \\
\text { de Bolivia }\end{array}$ & Provincia & $\begin{array}{c}\text { Cantidad } \\
\text { de jornaleros }\end{array}$ & Porcentaje \\
\hline Cochabamba & $\begin{array}{c}\text { Departamento de } \\
\text { Cochabamba }\end{array}$ & Provincia de Cercado & 489 & $42,6 \%$ \\
\hline Quillacollo & $\begin{array}{c}\text { Departamento de } \\
\text { Cochabamba }\end{array}$ & Provincia de Quillacollo & 159 & $13,8 \%$ \\
\hline Sacaba & $\begin{array}{c}\text { Departamento de } \\
\text { Cochabamba }\end{array}$ & Provincia del Chapare & 21 & $1,8 \%$ \\
\hline Sipe Sipe & $\begin{array}{l}\text { Departamento de } \\
\text { Cochabamba }\end{array}$ & Provincia de Quillacollo & 42 & $3,6 \%$ \\
\hline $\mathrm{LaPaz}$ & $\begin{array}{l}\text { Departamento de } \\
\text { La Paz }\end{array}$ & $\begin{array}{c}\text { Provincia Pedro Domingo } \\
\text { Murillo }\end{array}$ & 22 & $1,9 \%$ \\
\hline Oruro & $\begin{array}{c}\text { Departamento de } \\
\text { Oruro }\end{array}$ & Provincia de Cercado & 74 & $6,4 \%$ \\
\hline Potosí & $\begin{array}{c}\text { Departamento de } \\
\text { Potosí }\end{array}$ & Provincia de Tomás Frías & 107 & $9,3 \%$ \\
\hline Sucre & $\begin{array}{c}\text { Departamento de } \\
\text { Chuquisaca }\end{array}$ & Provincia de Oropeza & 33 & $2,8 \%$ \\
\hline Uyuni & $\begin{array}{c}\text { Departamento de } \\
\text { Potosí }\end{array}$ & $\begin{array}{c}\text { Provincia Antonio } \\
\text { Quijarro }\end{array}$ & 53 & $4,6 \%$ \\
\hline Tupiza & Departamento de Potosí & Provincia de Sud Chichas & 21 & $1,8 \%$ \\
\hline Tarata & $\begin{array}{l}\text { Departamento de } \\
\text { Cochabamba }\end{array}$ & Provincia Esteban Arze & 19 & $1,6 \%$ \\
\hline Otros & & & 106 & $9.2 \%$ \\
\hline Total & & & 1.146 & $100 \%$ \\
\hline
\end{tabular}

Esquema: Elaboración propia. Fuente: Archivo Histórico Universidad Católica del Norte, Fondo Archivo de Extranjería del Registro Civil e Identificación de Antofagasta. 
Cochabamba es la ciudad desde donde provino la mayor cantidad de migrantes: 42,6\%. El poblado de Quillacollo, que es parte del departamento de Cochabamba y se encuentra a tan solo 13 $\mathrm{km}$ de la ciudad capital, aportó con 13,8\% de migrantes. La comunidad de Sacaba, también a 13 $\mathrm{km}$ de la ciudad de Cochabamba, aportó con 1,8\% de migrantes. Por su parte Sipe Sipe, pequeña localidad en el denominado Valle Bajo en el departamento de Cochabamba -y que se encuentra a solo $27 \mathrm{~km}$ al suroeste de la capital de este-, participó con 3,6\%. Agréguese Tarata, igualmente parte del mismo departamento y ubicada a $29 \mathrm{~km}$ de su capital, Cochabamba, con 1,6\%.

Entonces, con esos datos podemos afirmar que desde el departamento de Cochabamba provino el $63,4 \%$ de la migración, con una cifra absoluta de 727 jornaleros. Aquel departamento poseía una población aproximada de 40000 habitantes (Mesa et al., 2007) en el primer lustro de la década de 1920. Por lo mismo, es relevante destacar que tratamos acerca de una movilidad signada por la discontinuidad espacial o geográfica entre los espacios de origen y destino, sostenida en el enganche de trabajadores, y no como otras espacialidades migratorias que hemos documentado para el desierto de Atacama, donde la contigüidad espacial produce la escena para inscribir la movilidad en prácticas y economías familiares (Garcés et al., 2019, 2018; Garcés y Maureira, 2018).

La distribución cronológica de ingreso de estos jornaleros nos presenta el siguiente panorama en rangos de 10 ańos (Figura 2).

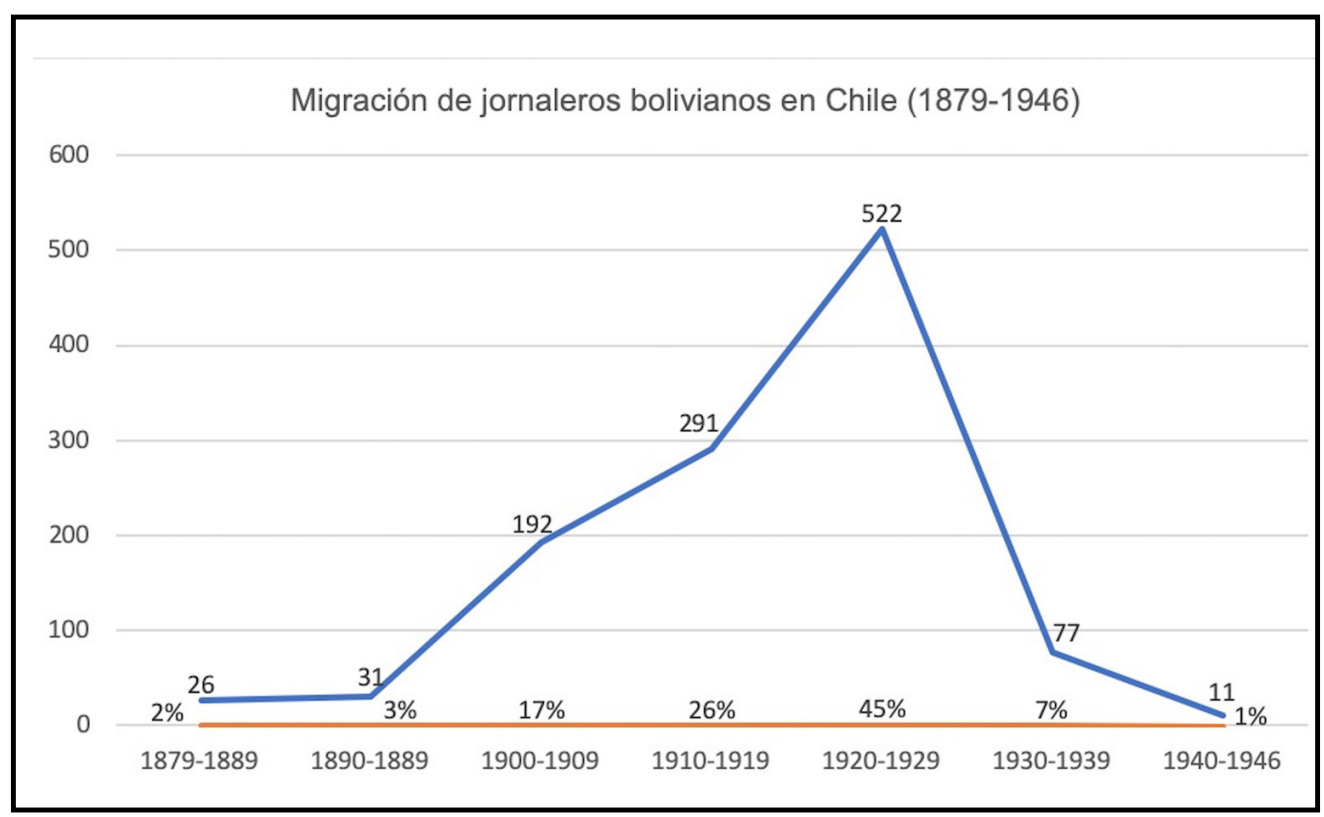

Figura 2. Análisis de la migración boliviana en Chile en rangos de 10 años. Esquema: Elaboración propia. Fuente: Archivo Histórico Universidad Católica del Norte, Fondo Archivo de Extranjería del Registro Civil e Identificación de Antofagasta.

El 37,2\% (lo que significa 427 jornaleros) declaró que no sabía leer ni escribir. Por su parte, el $62,3 \%$ (714 jornaleros) indicó que sí lo sabía hacer. El resto de la muestra no entregó información, $0,5 \%$ (5 jornaleros). En cuanto al estado civil se presenta lo siguiente (Tabla 4). 
Tabla 4. Cuantificación del estado civil de los jornaleros bolivianos.

\begin{tabular}{|c|c|c|c|c|c|c|}
\hline Solteros & Solteras & Casados & Casadas & Viudos & Viudas & No Indica \\
\hline 524 & 7 & 552 & 10 & 51 & 1 & 1 \\
\hline
\end{tabular}

Esquema: Elaboración propia. Fuente: Archivo Histórico Universidad Católica del Norte, Fondo Archivo de Extranjería del Registro Civil e Identificación de Antofagasta.

Considerando que 18 mujeres se presentaron como jornaleras, la migración femenina representa tan solo el 1,5\%. De ellas, 11 declararon que sabían leer y escribir. Por su parte, siete se identificaron como analfabetas.

\section{La escena cochabambina}

Sobre el escenario cochabambino, cabe indicar que para variados procesos mineros metálicos y no metálicos, los latifundios de dicho departamento boliviano fueron fundamentales para proporcionar diversos granos, frutas, harina, legumbres y hortalizas. Así queda demostrado por ejemplo en su rol de proveedora para los campamentos de la Compañía Huanchaca y el campamento de la mina Pulacayo (Galaz-Mandakovic, 2016). En ese marco, también se inscribió la industria salitrera que recibía desde Cochabamba diversos productos desde antes de la guerra, entre ellos los zapatos (Rodríguez, 1990; Henríques, 2015). No obstante, la Guerra del Pacífico (1879) bloqueó el mercado boliviano hacia la costa y, por efecto del Protocolo Complementario de 1885 , se impusieron franquicias aduaneras favorables para que productos chilenos ingresaran a Bolivia (Rodríguez, 2014). Adicionalmente, la construcción del Ferrocarril de Antofagasta a Bolivia hizo que Uyuni y Oruro desplazaran en importancia a Cochabamba, ya que por el ferrocarril ingresaban productos chilenos que desarmaron el mercado cochabambino. Por ejemplo, la harina cochabambina puesta en La Paz era 25,6\% más cara que la que provenía desde Antofagasta y 17,6\% más respecto de la harina procedente de Mollendo. Del mismo modo, perdían sus mercados la producción de tocuyos y diversos cereales (Henríques, 2015, p. 85).

Por efecto del ferrocarril, que ingresó a Bolivia en 1889 por Uyuni y en 1892 llegó a Oruro, esta última ciudad se transformó en el "verdadero centro motor del liberalismo" (Mesa et al., 2007, p. 41), llegando a duplicar su población. Lo mismo en Uyuni-ciudad que se transformó en la capital ferroviaria de Bolivia, con grandes maestranzas-, que atestiguó un apogeo comercial que devino en la conformación de una ciudad cosmopolita hacia donde confluían también indígenas y campesinos reconvertidos hacia la minería argentífera y la mecánica de los trenes (Galaz-Mandakovic, 2016, 2018b). Así fue que, en el marco de una densa crisis, algunos hacendados cochabambinos comenzaron con un proceso de fragmentación de sus propiedades surgiendo, de ese modo, una gran cantidad de parceleros. Según datos recogidos por Gustavo Rodríguez Ostria, en el período 1908 y 1916 se contabilizaban 28550 propiedades, lo que significaba prácticamente una triplicación de la cantidad registrada a fines del siglo XIX. Ese fenómeno dio pie a una diferenciaron entre los propios campesinos. Agréguese a lo anterior una serie de crisis relacionadas con sequías. Los períodos de escasez de lluvias habrían vulnerado la capacidad de mantener volúmenes estables de producción de cereales e influyó negativamente en la predisposición de los agricultores a invertir en infraestructura y tecnologías productivas (Henríques, 2015, p. 42). 
Fue así que, "como un torrente imparable, los campesinos optaron por el camino de la migración hacia las salitreras de la costa del Pacífico" (Rodríguez, 1990, p. 17). Del mismo modo lo harían hacia algunas minas de estaño (Mesa et al., 2007) y hacia la minería de la plata (López Pérez, 2011). Aquellos migrantes difundieron la chicha cochabambina, pero no sería suficiente para compensar la "declinación mercantil en otros productos" (Rodríguez, 1990, p. 21) que ya estaban en franco deterioro.

Como se pudo apreciar en la Figura 2, la migración de bolivianos hacia Chile disminuyó fuertemente desde finales de la década de 1920: el desmantelamiento de las salitreras del sistema Shanks y el impacto de la Gran Depresión de 1929 forzaron la declinación de la migración boliviana. Cabe indicar que, desde ese mismo final de década, Cochabamba vivía un resurgimiento por efecto de la nacionalización de la industria alcoholera por decisión del presidente José Manuel Justiniano Gutiérrez Guerra. Dicha nacionalización demandó una mayor explotación de las cañas de azúcar y de los maizales de los valles cochabambinos impulsando, además, la producción de las destilerías. El decreto indicaba en su Art. 1: "queda prohibida la importación de alcoholes y aguardientes extranjeros" (AGOB, lei del 23 de enero de 1918).

En el año 1917 se consumía un 1\% de maíz, sin embargo entre 1923 y 1925 aumentó a un $37 \%$ (Rodríguez, 1990). No obstante, dicha industria sufriría los vaivenes propios del mercado al ser amenazada por el contrabando, el alza de los fletes y la competencia internacional.

\section{El caso de la Oficina salitrera María}

El lugar declarado como destino en Chile por parte de los jornaleros presenta los siguientes guarismos entre los años 1879 y 1946 (Tabla 5).

Como puede apreciarse en la Tabla 5, gran parte de las salitreras en las cuales se conglomeraron los migrantes bolivianos remite al Cantón Central. Dicha zona salitrera fue menos productiva en referencia a Tarapacá y El Toco, al menos hasta antes de la Primera Guerra Mundial, pero creció en forma adyacente a un ferrocarril internacional que facilitó una movilidad significativa en cuanto a la fuerza de trabajo. De hecho, la Oficina María "se encuentra a 1 kilómetro al N de la línea férrea” (Riso Patrón, 1924, p. 530).

Curiosamente, en la revisión de la base de datos, ningún jornalero aparece con destino a la Oficina Chacabuco, la cual se construyó entre 1922 y 1924, deviniendo al poco tiempo en la principal salitrera del sistema Shanks en la zona antofagastina. Debemos consignar que según el Censo de 1920, en el departamento de Antofagasta de registraron 1816 jornaleros chilenos, y tan solo 31 extranjeros. Según nuestros datos, en 1920, siete jornaleros bolivianos se dirigieron a la ciudad de Antofagasta. El Censo de 1920 no detalla la subdivisión del departamento. ${ }^{6}$ La Oficina salitrera María estaba ubicada entre el poblado de Baquedano y Sierra Gorda, en la zona denominada Pampa Central, en el curso que marcó el ferrocarril que unió Antofagasta con Uyuni (FCAB) (Figura 3). Dicha mina pertenecía a la Compañía Salitrera El Loa,

6 Cabe indicar que 133 jornaleros se distribuyeron en diversos poblados de destino, tales como Yuma, Ujina, Tocopilla, Santa Rosa, San Pedro de Atacama, Puquios, Polapi, Pampa Unión, Palpana, Oficina Sargento Aldea, Oficina Rosario, Oficina Puelma, Oficina Prosperidad, Oficina Perseverancia, Oficina Mapocho, Oficina Los Dones, Oficina Francisco Vergara, Oficina Edén, Oficina Dominador, Oficina Chinta, Oficina Chacabuco, Oficina Curicó, Oficina Coya Sur, Oficina Concepción, Oficina Cecilia, Oficina Carmela, Oficina Candelaria, Oficina Buenaventura, Oficina Bonasort, Oficina Aurelia, Oficina Almagro, Estación Baquedano, Estación San Pedro, azufrera Amincha y la mina de plata de Caracoles. 
Tabla 5. Identificación de los poblados de destino de los jornaleros bolivianos.

\begin{tabular}{|c|c|c|}
\hline Destino en Chile & Cantidad & Porcentaje \\
\hline Of. María (Cantón Central) & 135 jornaleros & $11,7 \%$ \\
\hline Antofagasta & 101 jornaleros & $8,8 \%$ \\
\hline Cebollar & 79 jornaleros & $6,8 \%$ \\
\hline Of. Aconcagua (Cantón Central) & 75 jornaleros & $6,5 \%$ \\
\hline Of. Cecilia (Cantón Central) & 74 jornaleros & $6,4 \%$ \\
\hline Collahuasi & 67 jornaleros & $5,8 \%$ \\
\hline Of. Luisis (Cantón Central) & 64 jornaleros & $5,5 \%$ \\
\hline Chuquicamata & 60 jornaleros & $5,2 \%$ \\
\hline Of. Araucana (Cantón Central) & 52 jornaleros & $4,5 \%$ \\
\hline Ollagüe & 43 jornaleros & $3,7 \%$ \\
\hline Of. Lina (Cantón Central) & 39 jornaleros & $3,4 \%$ \\
\hline Of. Edwards (Cantón Central) & 38 jornaleros & $3,3 \%$ \\
\hline Of. José Santos Ossa (Cantón Central) & 37 jornaleros & $3,2 \%$ \\
\hline Of. Candelaria (Cantón Central) & 36 jornaleros & $3,1 \%$ \\
\hline Of. Anita (Cantón Central) & 36 jornaleros & $3,1 \%$ \\
\hline Of. Filomena (Cantón Central) & 32 jornaleros & $2,7 \%$ \\
\hline Of. Pinto (Cantón Central) & 25 jornaleros & $2,1 \%$ \\
\hline Calama & 23 jornaleros & $2,0 \%$ \\
\hline Of. Prat (Cantón Central) & 19 jornaleros & $1,6 \%$ \\
\hline Of. Leonor (Cantón Central) & 14 jornaleros & $1,2 \%$ \\
\hline Otros & 133 jornaleros & $11,6 \%$ \\
\hline Total & 1.146 jornaleros & $100 \%$ \\
\hline
\end{tabular}

Esquema: Elaboración propia. Fuente: Archivo Histórico Universidad Católica del Norte, Fondo Archivo de Extranjería del Registro Civil e Identificación de Antofagasta.

empresa que publicó sus estatutos en 1905, los que fueron aprobados por Decreto Supremo el 13 de septiembre del mismo año. Esta compañía era administrada y representada en la ciudad de Antofagasta por los agentes de Buchanan Jones y Cía., firma británica que desarrolló actividades en Iquique y en Pisagua y abordó la industria salitrera y la elaboración de yodo. “[E]n pocos ańos, la empresa adquirió enorme incremento, con benéficos resultados para los intereses chilenos a la vez que para los fondos sociales" (R.V.Y.V.,1925, p. 131). Hacia la década de 1910, la Compañía Salitrera El Loa llegó “a ser la más importante" (Bermúdez, 1967, p. 5) en el Cantón Central, conocido también como Cantón Bolivia.

7 Esta empresa tuvo como denominación inicial James, Inglis y Cía., también Inglis, Lomax y Cía., finalmente derivó en Buchanan, Jones y Cía., "nombres que corresponde a sus principales socios". (R.V.Y.V., 1925, p. 134). 


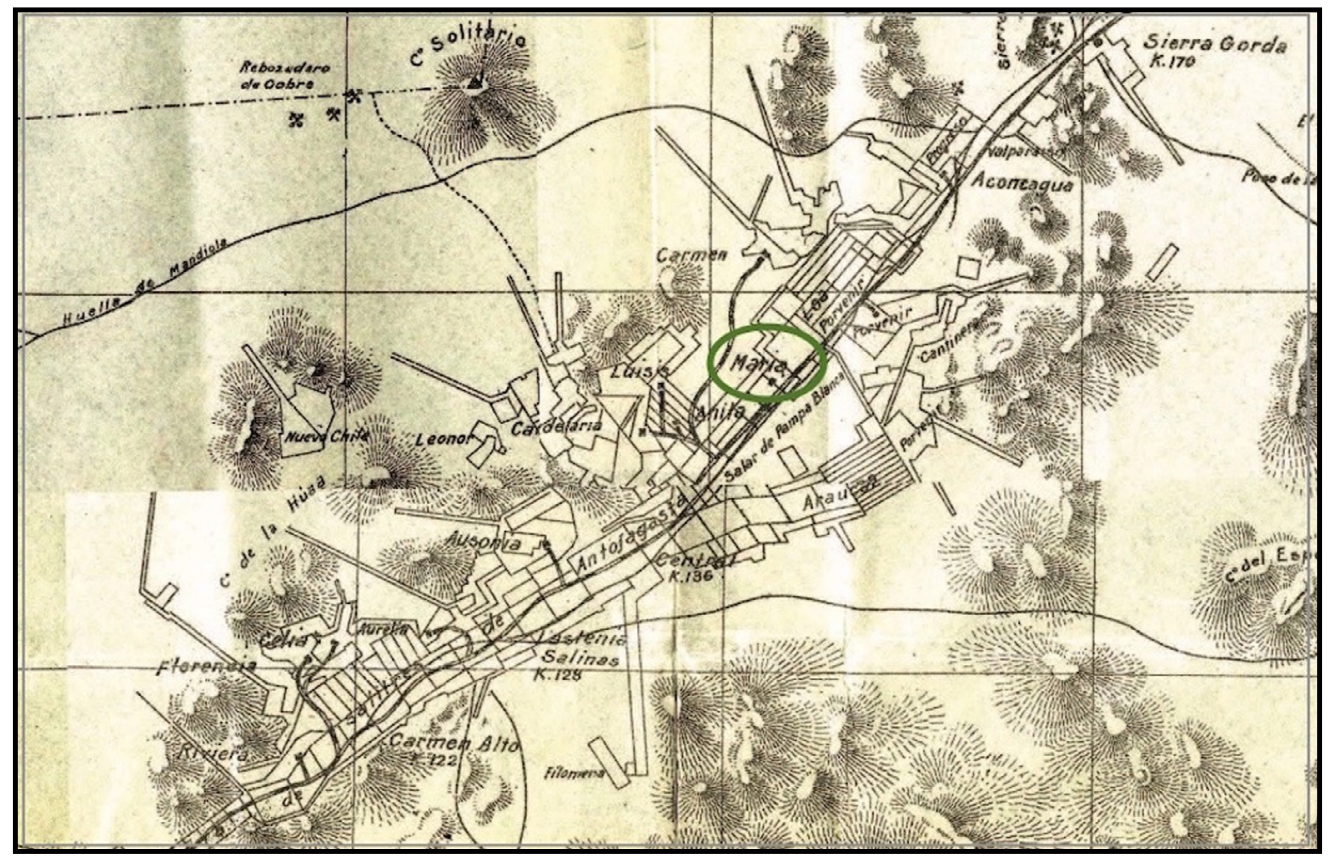

Figura 3. Detalle intervenido del mapa del distrito salitrero de Antofagasta, concerniente al Cantón Central en donde se ubicaba la Oficina salitrera María. Fuente: Semper E. y E. Michels (1908),

La industria del salitre en Chile. Santiago: Imprenta Barcelona.

En el año 1912, se noticiaba que la Compañía Salitrera El Loa “compró las Oficinas salitreras María, Curicó, Angamos, Anita, Luisis y Candelaria por la suma de \$ 3.500 .000 oro” (Pan American Union, 1912, p. 203), indicándose además que se proyectaba la producción de yodo. La compañía administraba 14000 ha (The American Fertilizer, 1920, p. 154). El puerto por el cual se exteriorizó la producción de María fue Mejillones, como también lo hacían las otras oficinas que pertenecían a la compañía, tales como las oficinas Aconcagua, Filomena, Araucana, Perseverancia, Ausonia y Celia, centros productivos en donde también allegaron bolivianos.

Según los datos publicados en el año 1913 en la Guia administrativa, industrial y comercial de las Provincias de Tacna, Tarapacá y Antofagasta, la Oficina salitrera María fue instalada con 11 estacas $^{8}$ chilenas y una boliviana. Contó con la implementación de 24 cachuchos de 32 pies de largo, además de 212 bateas, más seis calderos dobles de origen alemán, seis acendraderas ${ }^{9}$ de 24 por 15 pulgadas; dos ascensores eléctricos y un descensor de palanca. La Casa de Fuerza de dicha oficina contaba con una potencia de 400 caballos (había sido fabricada por Davey Paxman, de Inglaterra) con distribución por válvulas, sistema Lentz, alemán; tres calderos de alta presión, de 14 pies de largo por 7.5 de diámetro, con sobrecalentador; dos locomóviles de 185 caballos cada uno (Fábrica R. Wulf, Magdeburg Buckan, Alemania) con distribución de precisión por tirador pistón. "Esta Casa de Fuerza, cuya instalación es notable y muy poderosa, proporciona toda la energía necesaria a las máquinas de María, Curicó y Angamos, ex-Carmen” (Silva, 1913, p. 352). De ese modo, María era el centro energético de las oficinas de la Compañía Salitrera El Loa gracias a la instalación de "tres líneas elevadas" (Silva, 1913,

8 Una estaca es una concesión de un millón de metros cuadrados de terrenos calichosos.

9 Máquinas para triturar el caliche, posteriormente se denominaron chancadoras. 


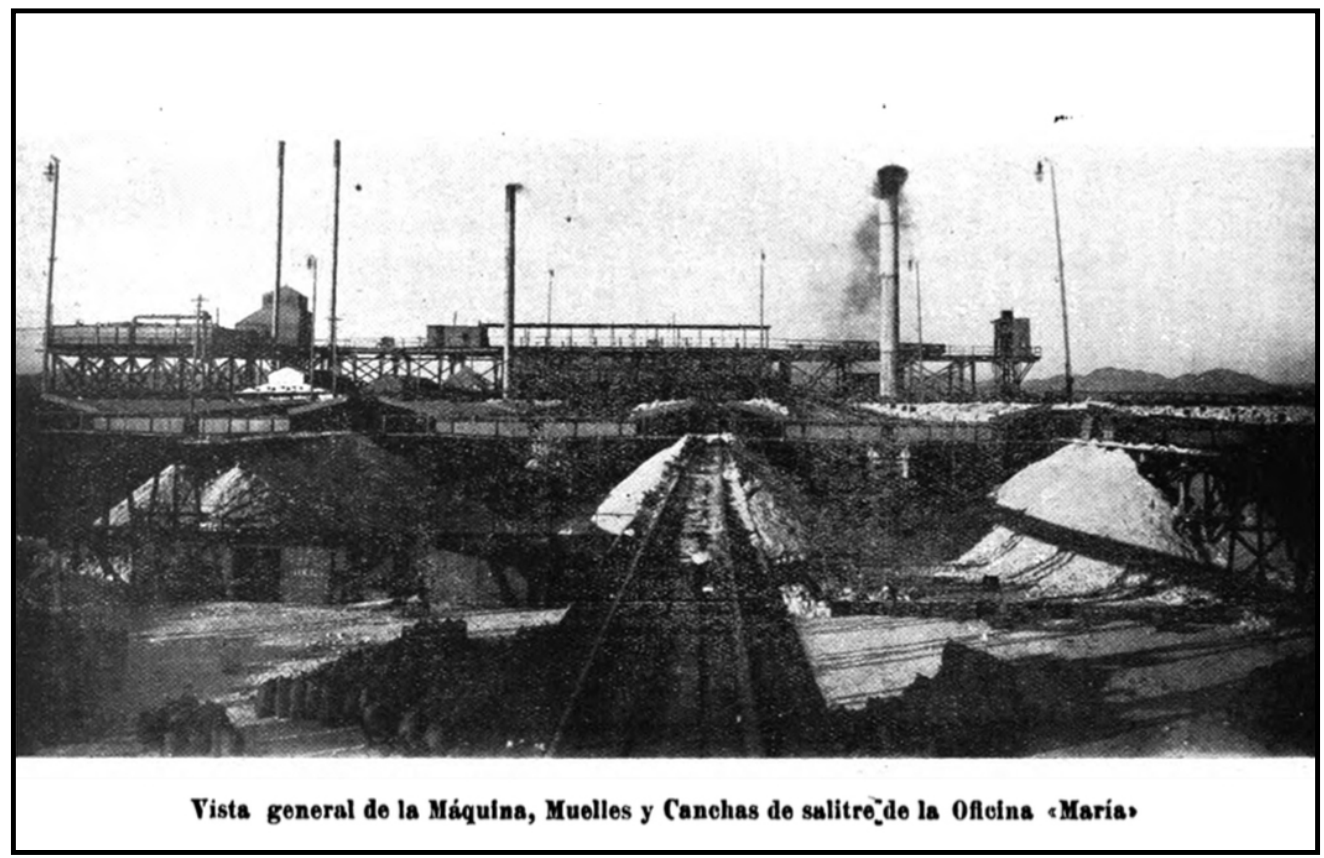

Figura 4. Vista general de la Máquina de elaboración, los muelles y las canchas de salitre de la Oficina María. Fuente: Silva, D. (1913), Guia administrativa, industrial y comercial de las provincias de Tacna, Tarapacá y Antofagasta. Imprenta y encuadernación "Chile".

p. 354). Asimismo, contaba con la denominada Casa de Yodo, que contenía dos aparatos para hacer licor, con dos hornos de azufre, seis bateas o estanques para cortar yodo. Agréguense tres prensas, cinco retortas, dos bombas Cameron y un compresor de aire para los hornos de azufre (Silva, 1913) (Figura 4).

Evidentemente, el caso de la Oficina salitrera María es sorprendente y revelador en cuanto a concentrar la mayor cantidad de mano de obra boliviana: 135 jornaleros. El 99,7\% de ellos ingresó por el paso fronterizo de Ollagüe. De esos 135 casos de jornaleros, 105 llegaron entre los ańos 1920 y 1923, es decir, en el mencionado período se concentró el 77,7\% de toda la migración de jornaleros bolivianos hacia la Oficina María. En cuanto a sus orígenes, el 27,4\% provenía de Cochabamba; el 20,7\% de Quillacollo y desde Sipe Sipe provenía el 6,6\%, comunidades pertenecientes todas al departamento de Cochabamba. En sumatoria, desde dicha región boliviana provino el $54,7 \%$ de ellos.

Sobre el estado civil de esta migración, se presentan 71 casados, 58 solteros, cinco viudos y uno que no indica su condición. ${ }^{10}$ En lo referente a su alfabetización, un 36\% de los migrantes declaró no saber leer ni escribir, y $64 \%$ mencionó que sí sabía hacerlo. Adicionalmente a esos 135 jornaleros, se atestigua también el arribo de otros 69 bolivianos que declararon diversas ocupaciones, entre ellos trabajadores conocidos como "particulares". ${ }^{11}$ (Tabla 6). En total, en la Oficina María se atestigua la presencia de 204 bolivianos (Figura 5).

10 Los prontuarios estudiados no señalan si acaso los jornaleros viajaban solos o con sus esposas.

11 El obrero conocido como "particular" era aquel que abría con pólvora las zanjas y extraía el caliche, luego desempeńaba el trabajo del apartado del material y realizaba el carguío a las carretas que debían transportar el caliche a las chancadoras. 
Tabla 6. Identificación de otros oficios de migrantes bolivianos con destino a la Oficina salitrera María entre 1920 y 1923.

\begin{tabular}{|c|c|c|}
\hline $\mathbf{1}$ albañil & $\mathbf{2}$ fogoneros & $\mathbf{1}$ mesero \\
\hline 1 cocinero & 1 huinchero & 3 músicos \\
\hline 1 electricista & 1 maquinista & 4 particulares \\
\hline 1 tejedor & 3 sombrereros & 1 motorista \\
\hline 1 zapatero & 2 talabarteros & 6 mecánicos \\
\hline 2 agricultores & 4 empleados & 1 minero \\
\hline 2 barreteros & 3 herreros & 10 obreros \\
\hline 3 comerciantes & 1 labrador & 1 no indica \\
\hline 4 carpinteros & 1 hojalatero & \\
\hline
\end{tabular}

Esquema: Elaboración propia. Fuente: Archivo Histórico Universidad Católica del Norte, Fondo Archivo de Extranjería del Registro Civil e Identificación de Antofagasta.

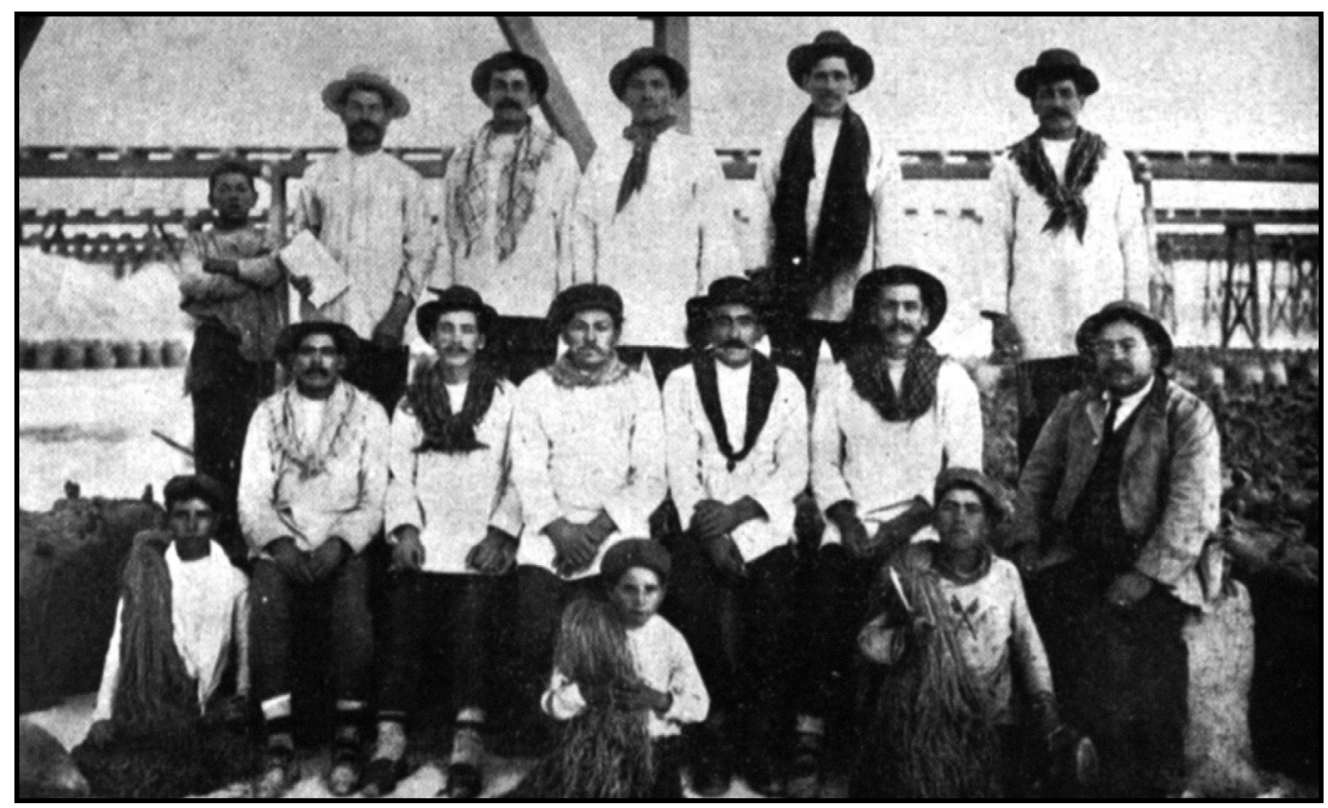

Figura 5. Cargadores de salitre y niños cosedores de sacos en la Oficina María. Fuente: Silva, D. (1913), Guía administrativa, industrial y comercial de las provincias de Tacna, Tarapacá y Antofagasta. Imprenta y encuadernación "Chile".

En términos demográficos, cabe indicar que según los censos de 1920 y 1930, en la Oficina María se presentan los siguientes guarismos, los cuales podemos comparar con la presencia de migrantes bolivianos en aquella mina (Tabla 7).

Se ha establecido que los primeros síntomas de una crisis estructural en la industria del salitre se manifestaron en los años previos a la Primera Guerra Mundial; fue este mismo acontecimiento bélico el que encubrió esos síntomas al demandar salitre refinado. Esa situación implicó que 
Tabla 7. Censos de la Oficina salitrera María comparados con la presencia de bolivianos.

\begin{tabular}{|l|c|c|c|c|c|c|}
\hline & Hombres & Mujeres & Total & \multicolumn{2}{|c|}{$\begin{array}{c}\text { Presencia de } \\
\text { jornaleros bolivianos }\end{array}$} & $\begin{array}{c}\text { Otros oficios y } \\
\text { profesiones }\end{array}$ \\
\hline Censo 1907 & 398 & 181 & 579 & Rango 1900-1907 & 9 & 2 \\
\hline Censo 1920 & 1.178 & 675 & 1.850 & Rango 1908-1920 & 27 & 16 \\
\hline Censo 1930 & 14 & 15 & 31 & Rango 1921-1923 & 99 & 47 \\
\hline & & & & Rango 1924-1930 & 0 & 2 \\
\cline { 4 - 7 } & & & & No indica & 0 & 2 \\
\cline { 4 - 7 } & & & & Subtotal & $\mathbf{1 3 5}$ & Subtotal: 69 \\
\hline
\end{tabular}

Nota. Fuente: Datos propios.

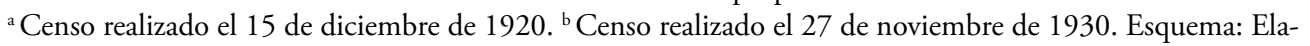
boración propia. Fuente: Censos de la República de Chile años 1907, 1920 y 1930 y Archivo Histórico Universidad Católica del Norte, Fondo Archivo de Extranjería del Registro Civil e Identificación de Antofagasta.

el ciclo de expansión continuara después de 1920. La producción de salitre relegó a segundo plano las exportaciones de trigo y harina y también la producción de cobre, plata y oro del Norte Chico (Cariola y Sunkel, 1982, p. 67). Esos indicadores aumentaron, al igual que la mano de obra y el número de oficinas salitreras (González, 2010, p. 93). Coincidentemente, las salitreras de Henry Sloman, por efecto de figurar en las llamadas "listas negras" y por el bloqueo de los barcos alemanes (La Nación, 20 de julio 1917), significó el periclitar de las salitreras alemanas ubicadas en el Cantón El Toco. ${ }^{12}$ Aquel escenario significó que el papel productivo fuese trasladado a las oficinas del Cantón Central. De este modo, podemos anotar que en el año 1910, la Oficina María producía 951000 quintales españoles de salitre (Cariola y Sunkel,1982). En 1913, la Compañía Salitrera El Loa reportaba con sus seis oficinas 3948 555 quintales españoles de salitre (Hernández, 1930). En 1917, produjo casi 212000 toneladas (The American Fertilizer, 1920). En el año 1923 la Oficina María poseía una magnitud de elaboración mensual de “4.740 toneladas de capacidad productiva” (Riso Patrón, 1924, p. 530). Fue ahí cuando la mano de obra boliviana, particularmente desde 1920, participó en un proceso productivo que tuvo sus estertores en el final del primer lustro de la década de 1920. Finalizando la década, Guggenheim Brothers, a través de The Anglo Chilean Consolidated Nitrate Corporation, compró la Compañía El Loa, la cual poseía "una gran extensión de tierras de nitrato" (American Fertilizer, volumen 70, 1929, p. 42), ubicadas contiguamente a los terrenos de los estadounidenses.

\section{Sujetos y sociabilidad}

En términos estadísticos, la presencia de bolivianos se aglutina entre los años 1920 y 1923; no obstante, hallamos una importante referencia que nos expide hacia el año 1912, dato que nos alerta sobre la densidad de la presencia boliviana y sobre la inserción laboral y participación social que desplegaron. Según nuestros datos, hasta 1912, los prontuarios de extranjería indican

12 Otro mecanismo de sabotaje hacia los alemanes fue obstaculizar el acceso a los sacos de yute usados para envasar el nitrato; esos envases eran provistos por la empresa inglesa Bank Line (Couyoumdjian, 1986). Igualmente, restringirles totalmente el acceso al petróleo por parte de las empresas norteamericanas fue crucial para inducir la quiebra empresarial de Henry Sloman (Galaz-Mandakovic, 2019). 
la presencia de 14 jornaleros bolivianos, además de un albañil, un herrero y un mecánico, es decir, en términos regulares, solo se constata la presencia de 17 bolivianos en la Oficina salitrera María.

La presencia de trabajadores bolivianos no es explicitada en la Guia administrativa, industrial y comercial de las Provincias de Tacna, Tarapacá y Antofagasta (1913). No obstante, puede ser advertida con tres llamativos detalles fotográficos. Así fue que, gracias a esta fuente, podemos ver que los trabajadores bolivianos crearon un club social llamado "Centro Boliviano Pedro Domingo Murillo”, organización que posa para la fotografía junto a una bandera boliviana, en la cual aparecen más de 30 personas, específicamente hombres adultos, jóvenes y algunos niños (Figura 6).

Podemos ver que dicho centro incorporó la creación de un Team de Foot-Ball, compuesto por 11 jugadores que aparecen vestidos con su uniforme (Figura 7).

Otro interesante registro fotográfico retrata una actividad en la que los integrantes del equipo de fútbol lucen trajes de fantasías durante la celebración del 18 de septiembre de 1912. (Figura 8). Cabe indicar que usualmente la Máquina -chancado y elaboración- "suspendía sus labores solo durante la celebración de Fiestas Patrias" (Matus, 2013, p. 514).

Los archivos fotográficos no indican los nombres de los bolivianos fotografiados, a diferencia de las otras fotografías que aparecen en dicha Guia administrativa, industrial y comercial de las Provincias de Tacna, Tarapacá y Antofagasta de 1913, en donde se individualiza a cada uno de los administradores, jugadores de fútbol y bomberos de las Oficinas de la Compañía Salitrera El Loa.

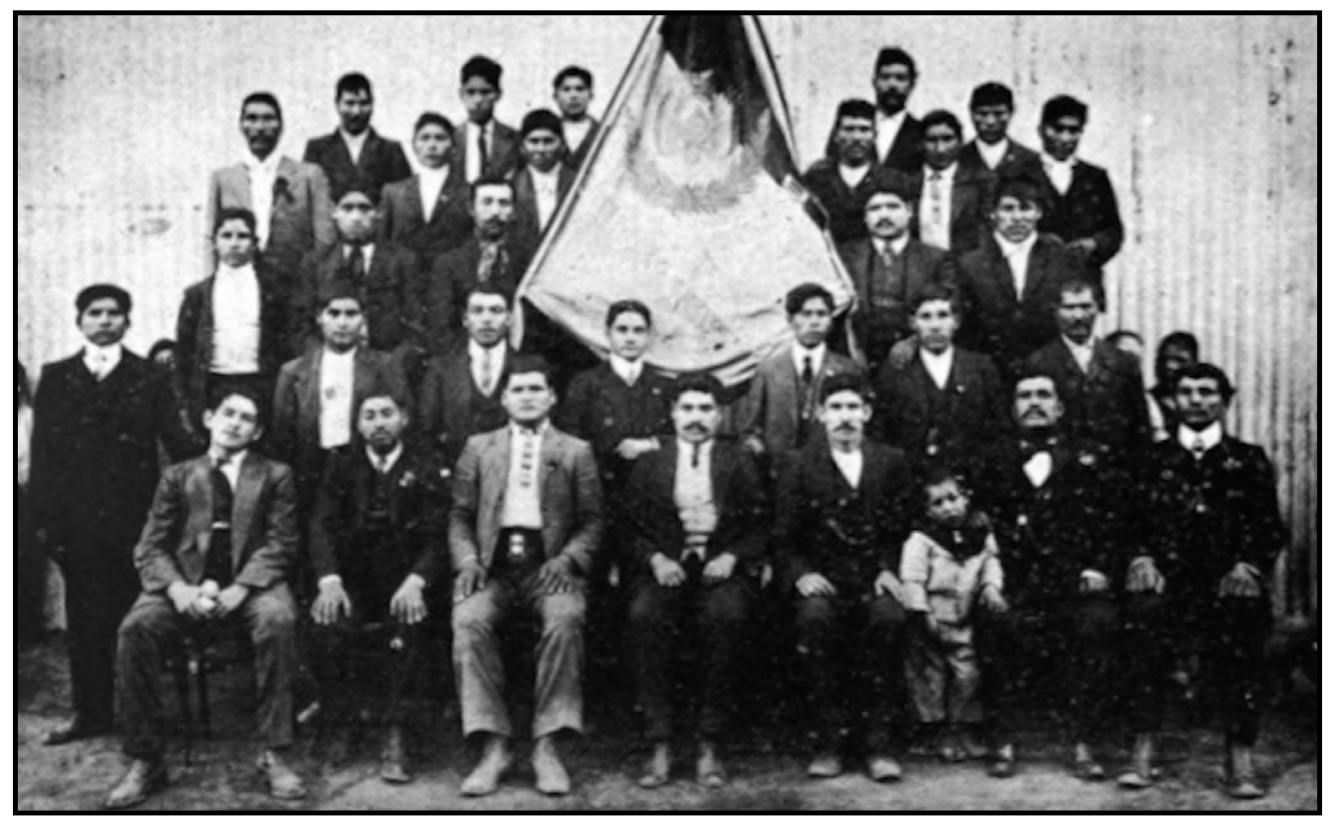

Figura 6. Centro Boliviano Pedro Domingo Murillo en la Oficina María. Fuente: Silva, D. (1913), Guía administrativa, industrial y comercial de las provincias de Tacna, Tarapacá y Antofagasta. Imprenta y encuadernación "Chile". 


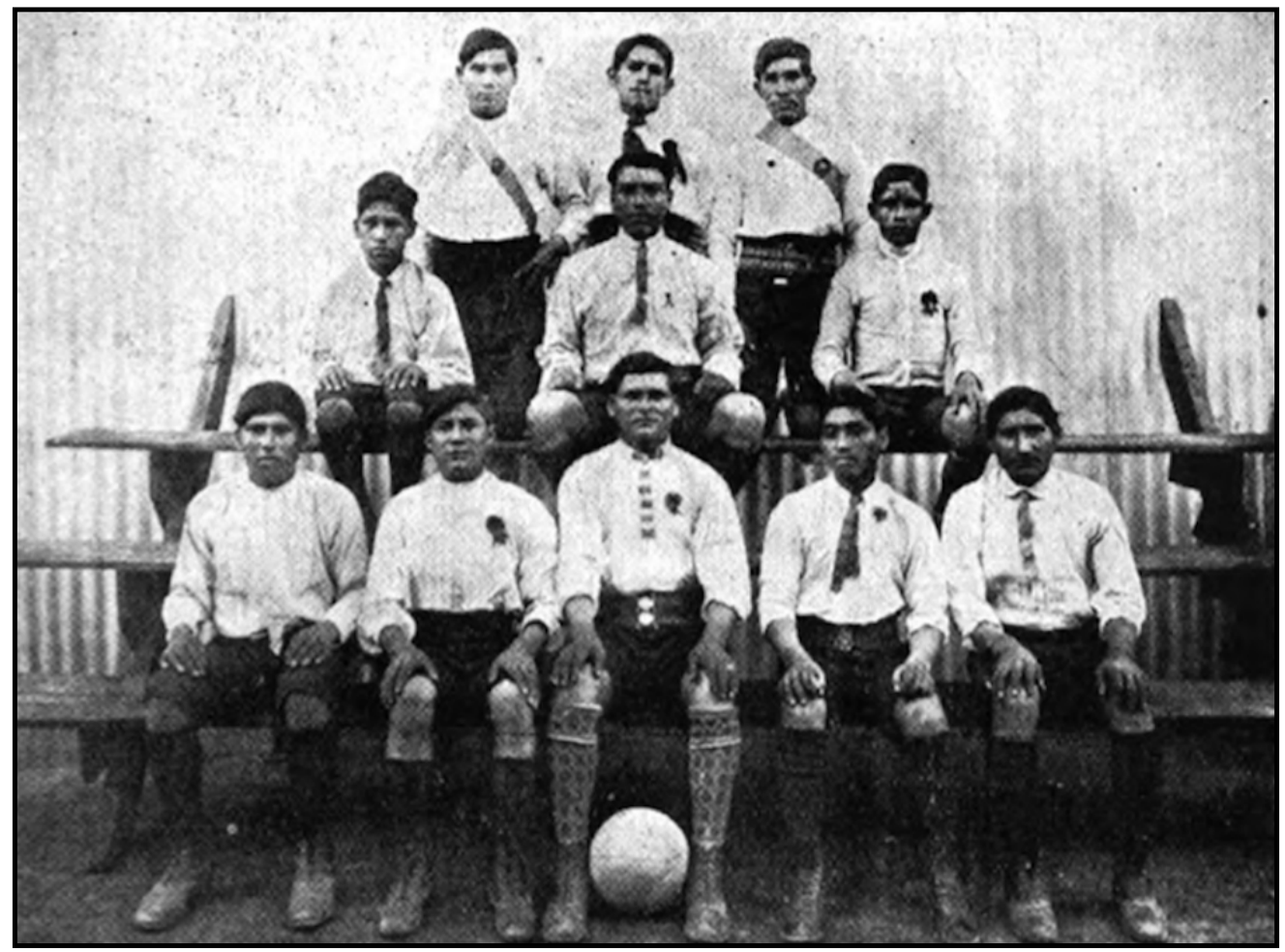

Figura 7. Equipo de fútbol perteneciente al Centro Boliviano Pedro Murillo de la Oficina salitrera María. Fuente: Silva, D. (1913), Guia administrativa, industrial y comercial de las provincias de Tacna, Tarapacá y Antofagasta. Imprenta y encuadernación "Chile".

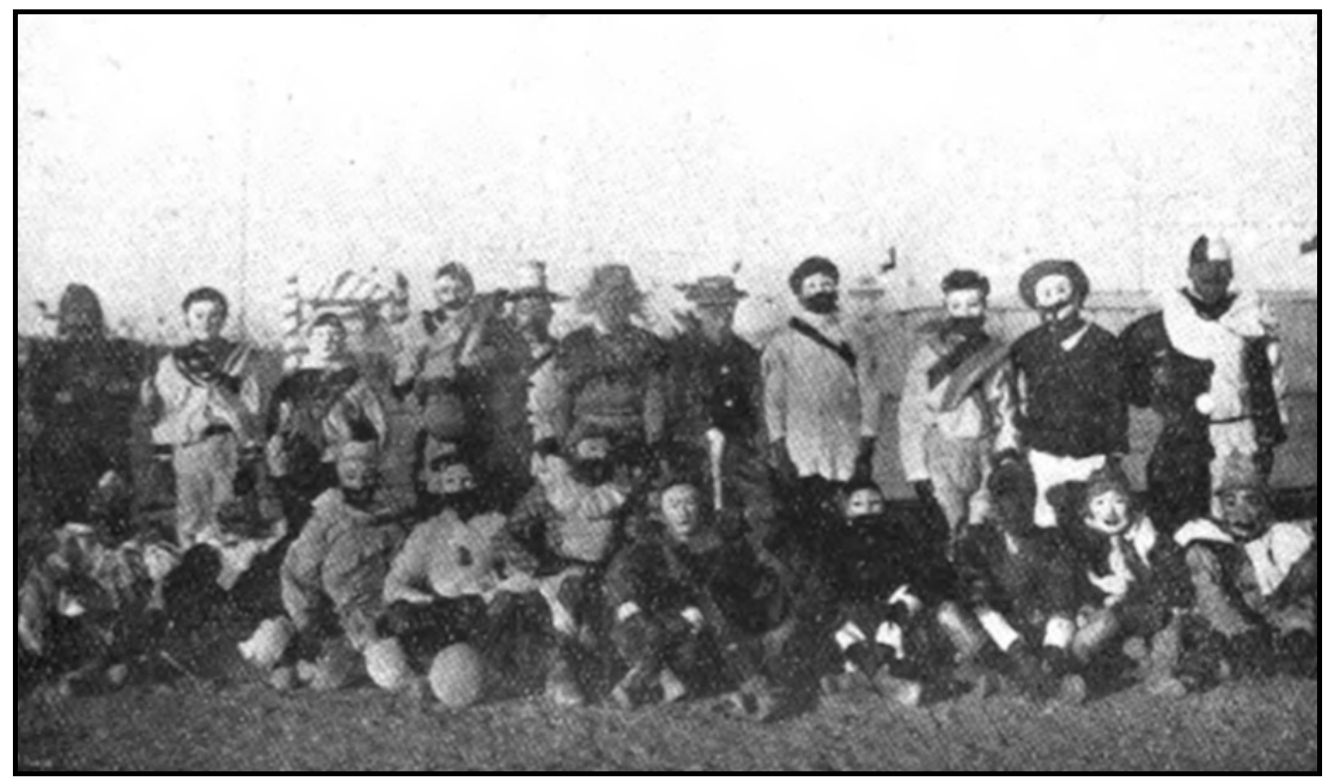

Figura 8. Equipo de fútbol del Centro Boliviano Pedro Murillo de la Oficina salitrera María en traje de comparsa para celebrar un partido durante las Fiestas Patrias de Chile en 1912. Fuente: Silva, D. (1913), Guía administrativa, industrial y comercial de las provincias de Tacna, Tarapacá y Antofagasta. Imprenta y encuadernación "Chile". 


\section{Conclusión}

La presencia de bolivianos durante el fin del ciclo de expansión de salitre nos da cuenta de la magnitud del fenómeno migrante y de la centralidad que ocupó esta mano de obra jornalera en el despliegue de las faenas mineras. De este modo, pudo observarse cómo el capitalismo minero produjo una mano de obra subalterna en un territorio donde, en los hechos, estos hombres se negaron a perder su bolivianidad junto con resistirse a un fenómeno de chilenización. El descenso cuantitativo de dicha migración también estuvo inscrito en el desmantelamiento de las salitreras y en el mejoramiento de la escena productiva en Cochabamba. En el decir de Alejandro Soto, hacia la década de 1920 "el indígena boliviano que había proporcionado gran parte de la mano de obra barata hasta entonces, había desaparecido" (Soto, 1998, p. 633). En el segundo lustro de la década de 1920 surgió el agotamiento de los salitrales de alta ley, junto con el encarecimiento del transporte del salitre hasta los puertos. De este modo, las empresas acusaban deudas y obsolescencias tecnológicas.

En ese sentido, en ese transcurrir de la crisis, la apuesta para el beneficio económico de los empresarios radicó en la baja cualificación por encima de la inversión en capital (Matus, 2013) y en las bajas remuneraciones para aquellos individuos desplegados en labores de destazamien$t o^{13}$-usualmente niños-, en el traslado del caliche en carretas, para los que trabajaban en las chancadoras, los que retiraban el ripio de los cachuchos, los que limpiaban la máquina, los que atendían las bateas lixiviadoras, los que acarreaban el carbón y alimentaban las calderas, los que con pala aglutinaban el salitre para luego ensacarlo y así, seguidamente, cargar los sacos en los ferrocarriles.

De esta manera, los capitales salitreros generaron una acumulación sobre la base de un subsidio étnico internacional de la mano de obra subalterna de origen boliviano. Dicho subsidio estaba sustentado en una asimetría relacional y étnica que proporcionó las fuerzas del trabajo más duro y, a la vez, el más barato en el desierto de Atacama, sobre las cuales se construyeron semánticas e imágenes específicas para retratarlas; en el decir de Achille Mbembe, "la acumulación siempre necesita de suplementos o subsidios raciales" (2016, p. 322).

Por otra parte, un poco más al norte, la arremetida de los Guggenheim en la industria del salitre significó la disminución de mano de obra: eran pocas las oficinas y, además, su sistema tecnológico electromecanizado era mucho más eficiente (Galaz-Mandakovic, 2018). En las salitreras del sistema Guggenheim (María Elena y Pedro de Valdivia) 7000 hombres producían 70000 toneladas de salitre. Mientras que en las plantas del sistema Shanks, como en la de la Oficina María, 9000 hombres producían tan solo 30000 toneladas de salitre en promedio (Soto, 1998, p. 633). Ese escenario estimuló una crisis económica y social, y el desierto fue atestiguando la borradura de sus poblados mientras también las migraciones bolivianas presentaban un descenso, aunque dejaron la memoria de una participación que ha sido despreciada e incluso invisibilizada. La Oficina María o el llamado Cantón Bolivia nos hablan de la persistencia de una bolivianidad en el territorio, supuestamente en retroceso frente a los dispositivos de la chilenización, pero actualizada en la forma de una migración.

13 El operario destazador era aquel que se ocupaba en ensanchar el fondo (raspando la tierra, la coba) para con los tiros de pólvora generar un mayor rompimiento. Este trabajo era realizado normalmente por niños (Echeverría y Reyes, 1929). 


\section{Agradecimientos}

Este artículo se enmarca en los resultados de los proyectos FONDECYT 1160963 "Espacialidades transfronterizas en el desierto de Atacama. Movilidad y reconfiguración de identidades nacionales y étnicas"; FONDECYT 11180932: “Chuquicamata, Cantón El Toco y Tocopilla bajo la impronta de los Guggenheim: sistemas técnicos, sociedad, conflictos y medioambiente en el desierto de Atacama (1915-2015)" y Núcleo Milenio Movilidades y Territorios MOVYT.

\section{Referencias citadas}

American Fertilizer (1920). American fertilizer and allied chemicals, 52. Philadelphia: Ware Bros.

American Fertilizer (1929). American fertilizer and allied chemicals, 70 Philadelphia: Ware Bros.

Bermúdez, O. (1967). Las oficinas salitreras adyacentes a la línea del ferrocarril de Antofagasta a Bolivia. Boletín de la Asociación de Geógrafos de Chile (apartado), 3, 1-10.

Cariola, C. y Sunkel, O. (1982). La historia económica de Chile: 1830 y 1930. Dos ensayos y una bibliografía. Madrid: Ediciones Cultura Hispánica del Instituto de Cooperación Iberoamericana.

Comisión Central del Censo 1907 (1908). Censo de la República de Chile 1907. Santiago: Imprenta Universo.

Compañía Salitrera El Loa (1905). Estatutos de la Compañia Salitrera El Loa aprobados por Decreto Supremo de 13 de septiembre de 1905. Valparaíso: Sociedad Imprenta y Litografía Universo.

Couyoumdjian, R. (1986). Chile y la Gran Bretaña durante la primera guerra mundial y la posguerra 19141921. Santiago: Editorial Andrés Bello y Ediciones de la Pontificia Universidad Católica de Chile.

Dirección General de Estadísticas (1920). IX Censo de la población de la República de Chile. Santiago: Soc. Imp. Litografía Universo.

Dirección General de Estadísticas (1930). X Censo de la población de la República de Chile. Santiago: Soc. Imp. Litografía Universo.

Echeverría y Reyes, A. (1929). Voces usadas en la industria salitrera. Antofagasta: Imprenta Skarnic.

Fernández Navas, P. (2015). La otredad incivilizada en el mundo del salitre. El caso de indígenas bolivianos e inmigrantes asiáticos en Tarapacá, 1900-1910. Polis, 42. Link: http://journals.openedition.org/ polis/11277

Galaz-Mandakovic, D. (2016). Industrialización minera, urbanización e innovación en las relaciones sociales en el sudoeste del altiplano boliviano: el caso de la Compañía Huanchaca de Bolivia (1834-1930). Estudios Atacameños. Arqueología y Antropología Surandinas, 52, 153-175. https://dx.doi.org/10.4067/ S0718-10432016005000001

Galaz-Mandakovic, D. (2018a). De Guggenheim a Ponce. Sistema técnico, capitalismo y familias en el extenso ciclo de los nitratos en El Toco y Tocopilla (1924-2015). Revista Chilena de Antropología, 37, 108130. https://revistas.uchile.cl/index.php/RCA/article/view/49486

Galaz-Mandakovic, D. (2018b). Emergencia y desarrollo urbano de Uyuni en su articulación argentífera con Antofagasta (1889-1902). Revista CIIAR, Museo Regional de Antofagasta. https://www.researchgate. 
net/publication/325676350_Emergencia_y_desarrollo_urbano_de_Uyuni_en_su_articulacion_argentifera_con_Antofagasta_1889-1902.

Galaz-Mandakovic, D. (2019). Movimientos, tensiones y luces. Historias tocopillanas. Tocopilla, Chile: Ediciones Bahía Algodonales.

Garcés, A., González, I., Richard, N. y Soto, L. (2018). Formas porosas. Tiempos, movilidad y economías de frontera entre San Pedro de Atacama y Lípez. Revista de Dialectología y Tradiciones Populares, LXXIII(2), 547-568.

Garcés, A. y Maureira, M. (2018). De familia a organización étnica: redes para una espacialidad transfronteriza en la Puna de Atacama. Revista Chilena de Antropología, 37, 230-248. DOI: 10.5354/07191472.2018 .49514

Garcés, A., Moraga, J., Maureira, M. y Saavedra, A. (2019). Desbordando la Puna de Atacama. Movilidad, economías y etnicidad (1950 al presente). Cahiers des Amériques Latines, 91, 49-69

González Miranda, S. (2002). Chilenizando a Tunupa. La escuela pública en el Tarapacá Andino 1880-1990. Santiago: Ediciones de la Dirección de Bibliotecas, Archivos y Museos, Centro Barros Arana.

González Miranda, S. (2009). La presencia boliviana en la sociedad del salitre y la nueva definición de la frontera: auge y caída de una dinámica transfronteriza (Tarapacá 1880-1930). Chungara. Revista de Antropología Chilena, 41(1), 71-81.

González Miranda, S. (2010). El cantón Bolivia o central durante el ciclo de expansión del nitrato. Estudios Atacameños. Arqueología y Antropología Surandinas, 39, 85-100.

González Pizarro, J. (2008). La emigración boliviana en la precordillera de la región de Antofagasta, 19101930. Redes sociales y estudios de casos. Revista de Ciencias Sociales (Cl), 21, 61-85.

González Pizarro, J. (2010). La industria minera de Antofagasta y la inmigración boliviana durante el ciclo salitrero. Notas para su estudio. Si Somos Americanos. Revista de Estudios Transfronterizos, X(2), 97-127.

González Pizarro, J., Lufin, M. y Galeno, C. (2015). La presencia boliviana en el desierto de Atacama después de la postguerra de 1879: patrones de migración e inserción en la sociedad de Antofagasta. Diálogo Andino, 48, 109-126.

Gutiérrez, E. y Figueroa, M. (1920). Chuquicamata: Su grandeza y sus dolores. Santiago: Imprenta Cervantes.

Henríques, R. (2015). Análisis de los niveles de vida y desigualdad en la ciudad de Cochabamba durante el primer siglo republicano, 1825-1925. Tesis doctoral. Facultad de Ciencias Económicas y Empresariales, Departamento de Economía Aplicada e Historia Económica, UNED, España.

Hernández, R. (1930). El Salitre: Resumen Histórico desde su Descubrimiento y Explotación. Valparaíso: Fisher Hermanos.

López, V. (2011). Uyuni: Historia de un pasado glorioso. Cochabamba: Editorial Adonai.

Matus, M. (2013). Fulgor y muerte del jornal salitrero en Chile, 1899-1930. En González, S. (Ed.). La Sociedad del Salitre. Santiago: RIL Editores.

Mbembe, A. (2016). Critique de la raison nègre. Paris: Éditions La Découverte. 
Mercado, J. (2007). Los inicios de la chilenización en Atacama: Una aproximación a las discursividades sobre el 'indio atacameño' durante la posguerra del Pacífico (1885-1910). Revista Electrónica Parinas, 3, $2-18$.

Mesa Gisbert, C. D., Mesa, J. de y Gisbert, T. (2007). Historia de Bolivia. La Paz: Editorial Gisbert.

Morales M, H. (2013). Construcción social de la etnicidad: ego y alter en Atacama. Estudios Atacameños. Arqueología y Antropología Surandinas, 46, 145-164. https://dx.doi.org/10.4067/S0718-10432013000200009

Oficina Central de Estadística en Santiago (1889). Sesto Censo Jeneral de la población de Chile levantado el 26 de noviembre de 1885 y compilado por la Oficina Central de Estadistica en Santiago. Valparaíso: Imprenta de "La Patria".

Pacheco, P. (1992). Integración económica y fragmentación social. El itinerario de las barracas en la amazonia boliviana. La Paz: CEDLA.

Pan American Union (1911). Boletín de la Unión Panamericana. Washington D.C.

Paz, D. (2009). Estructura agraria de boliviana. La Paz: Plural editores.

Recabarren, F. (2002). Episodios de la vida regional. Antofagasta: Ediciones Universitarias, Universidad Católica del Norte.

Recabarren, L. E. (1910). Ricos y Pobres. En Recabarren, L. E. (1971). El Pensamiento de Luis Emilio Recabarren. Tomo I (pp. 163-205). Santiago: Editorial Camino de Victoria.

Riso Patrón, L. (1924). Diccionario jeográfico de Chile. Santiago: Imprenta Universitaria.

Rodríguez, G. (1990). Estado nacional, mercado interior y élites regionales: los casos de Cochabamba y Santa Cruz en Bolivia, (1880-1930). Andes, 2-3, 11-32.

Rodríguez, G. (2001). Los Mineros de Bolivia en una Perspectiva Histórica Convergencia. Revista de Ciencias Sociales, 8(24). Universidad Autónoma del Estado de México. Toluca, México.

Rodríguez, G. (2014). Capitalismo, modernización y resistencia popular 1825-1952. La Paz: Vicepresidencia del Estado de Bolivia - Centro de Investigaciones Sociales.

R.V.Y.V. editores (1925). El esfuerzo británico en Valparaíso y álbum de Chile. Valparaíso: Casa Mackenzie.

Salazar, G. (1989). Labradores, peones y proletarios (Siglo XIX). (2a ed.), Santiago: Ediciones SUR.

Schumpeter, J. (1978). Teoría del desenvolvimiento económico. México, D.F.: Fondo de Cultura Económica.

Semper E. y Michels, E. (1908). La industria del salitre en Chile. Santiago: Imprenta Barcelona.

Silva, D. (2013). Guía administrativa, industrial y comercial de las provincias de Tacna, Tarapacá y Antofagasta. Santiago: Imprenta y encuadernación Chile.

S/N (1998). Glosario Pampino. Revista Camanchaca. Taller de estudios regionales, 6. Iquique-Chile.

Soto, A. (1998). Influencia británica en el salitre. Origen, naturaleza y decadencia. Santiago: Editorial Universidad de Chile.

Torreblanca, R. (1926). Por las tierras del oro blanco. Santiago: Editorial Iris. 


\section{Archivos}

ACBN: Archivo Congreso y Biblioteca Nacional de Chile.

AGOB: Archivo Gaceta Oficial de Bolivia.

AHUCN: Archivo Histórico Universidad Católica del Norte.

\section{Diarios y periódicos}

Diario La Nación, edición del 20 de julio 1917, Santiago.

Poncio Pilatos, edición jueves 26 de abril de 1894, Santiago. 